\title{
'Does the community use the built environment?' Assessing the utilization of healthy space model in bridging physical activity inequalities for the Thai population
}

\author{
Piyawat Katewongsa ${ }^{1,2}$, Dyah Anantalia Widyastari ${ }^{* 1,2}$, Panya Choolers ${ }^{1,2}$, \\ Wipada Iamyaem ${ }^{3}$ \\ ${ }^{1}$ Institute for Population and Social Research, Mahidol University, Thailand \\ ${ }^{2}$ Thailand Physical Activity Knowledge Development Center (TPAK), Thailand \\ ${ }^{3}$ Thai Health Promotion Foundation, Thailand
}

This study aims to assess the utilization of built environment under healthy space model for physical activity as a measure of inequalities in Thai communities. The mothodology included a cross-sectional survey with face-to-face interviews with a total of 2,046 community members. About $48 \%$ of the residents who lived near a sports complex have used the facility, while $22 \%$ and $31 \%$ of the locals have participated in the creative city and elderly healthy community. Compared to non-participants, sufficient MVPA was significantly higher among those who participated in the healthy space program $\left(\mathrm{t}=6.387^{* * *}\right)$. The results suggested that healthy space model could eliminate most socioeconomic inequalities but could not eliminate age-driven physical ability and social support inequalities in accessing PA amenities. The model could serve as an example for low-middle income countries where inequalities could not be neglected. The community engagement as the key of the model therefore is crucial, not only to make sure high participation but also in maintaining the built environment for PA.

Key Words: built environment, utilization, physical activity, inequalities, Thailand

Article Info: Received: April 8, 2020; Revised: May 10, 2020; Accepted: May 15, 2020; Online: May 23, 2020

\section{"Corresponding author}

Address: Institute for Population and Social Research, Mahidol University, Salaya, Phutthamonthon, Nakhon Pathom, 73170, Thailand.

Phone: +66-2411-0201-4/517 | Email: dyah.ana@mahidol.ac.th

(C)2020 Human Geographies; The authors

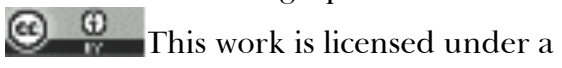

Creative Commons Attribution 4.0 International License. DOI:10.5719/hgeo.2020.141.7 


\section{Introduction}

The Thai government's 5-Year National NCD Prevention and Control Strategic and Action Plan (2017-2021) has targeted $80 \%$ of the Thai population being physically active in 2020 as a measure of NCD prevention (MoPH, 2017). This national strategic plan was formulated following the Bangkok Declaration on Physical Activity for Global Health and Sustainable Development in 2016 that emphasized the importance of physical activity for global health through the prevention of non-communicable diseases. It highlighted the co-benefits of population-based actions on physical activity and their contribution in achieving the 2030 sustainable development goals (SDGs) (ISPAH, 2017). The national strategy also reflects the country's commitment to supporting NCD global target 2025 by aiming at a $25 \%$ relative reduction in the overall mortality from cardiovascular diseases, cancer, diabetes, or chronic respiratory diseases, and $10 \%$ relative reduction in the prevalence of insufficient physical activity (WHO, 2013).

As a translation of the government's strategy into practice, various health promotion programs such as balanced nutrition, tobacco and alcohol control, salt reduction and physical activity have been implemented to encourage Thais to engage in healthy behaviour. Active People, Active Place, and Reducing Sedentary Behavior are among the existing programs to decrease the prevalence of inactivity of the Thai population, although their effectiveness remains a question. With the current figures; $66.3 \%$ of adults and only $26.2 \%$ of Thai children (IPSR, 2016, 2017; Saonuam et al., 2018) who met the WHO recommendation on sufficient $\mathrm{PA}$ (WHO, 2013), there is a chance that the current programs do not benefit the whole targeted population.

Previous studies reported that sufficient PA is determined by psychological, individual, social and also community factors such as built environment (Kärmeniemi et al., 2018; Liangruenrom et al., 2019; Zhang et al., 2019). Although it seems that individual factors were the strongest consistent predictor, it cannot be denied that the built environment has a vital role in enabling PA. Neighbourhoods with a high population density, right land-use mix, high connectivity, and good provision of walking/cycling facilities are more likely to encourage its inhabitants to use walking/cycling for transportation (Slater et al., 2016; Sones et al., 2019). While the Thai government has implemented various programs to increase PA level of its population, inequalities remain.

As the Thai population is socioeconomically diverse depending on education, income and occupation, richer Thais with higher educational attainment have more access to premium services, including for PA (Jitsuchon, 2020). The socioeconomic differentials in PA also occurred in many settings where the population with higher socioeconomic status (SES) was more physically active during leisure-time compared to those with lower SES, while occupational PA was more prevalent among the lower SES groups (Beenackers et al., 2012; GordonLarsen et al., 2006). Communities with higher SES had a significantly greater relative odds of having one or more PA facilities compared to the lower SES and high-minority groups (Gordon-Larsen et al., 2006). 
Although few studies documented the potential of the built environment in mitigating or exacerbating health inequalities (Slater et al., 2016; Sones et al., 2019), it is clear that built environment accessibility is also skewed toward the middle-high income families who mostly live in the city centre (Chandrasiri \& Arifwidodo, 2017). Socially-disadvantaged populations often reside in an environment which lacks access to amenities, that promote active mobility such as transit and recreational facilities, and eventually have more inadequate physical function than their more advantaged counterparts (Loh et al., 2019; Sones et al., 2019).

In Thailand, the existing built environment could only be accessed by half of the population (55.7\%) (IPSR, 2017). Of that half, $65.4 \%$ had good aesthetics, and $64 \%$ supported the safety of the population, while only $12 \%$ of sidewalks or bike lanes reported as in good condition (IPSR, 2016, 2017). The Urban Design and Development Center also reported that only $11 \%$ of Bangkok was accessible by foot; i.e. $60 \%$ of the inner-city area was not pedestrian-friendly. The reconstructtion of public parks has increased the number of youth (21\%) and elderly (33\%) who visit parks for leisure activity (Chandrasiri \& Arifwidodo, 2017). Unfortunately, public parks equipped with PA amenities are available mostly in the city centre and lacking in the outskirts or suburbs areas.

Considering the evidence on insufficient PA caused by inequalities (Beenackers et al., 2012; Chandrasiri \& Arifwidodo, 2017; Chase, 2018; Demarest et al., 2014; Giles-Corti, 2016; Gordon-Larsen et al., 2006; Jitsuchon, 2020), the Thai government opted to use built environment as one of the strategies to increase the standard of healthy living of its population. Numerous projects have been implemented in several communities to enable equal access to healthy spaces for PA. The healthy space itself was derived from the healthy city concept introduced by WHO in early 1990s as a fundamental approach to address urban health problem with community participation as the key feature (Petersen, 1996). Presently, healthy space has been used interchangeably to green space (Picavet et al., 2016; Roberts et al., 2018; Watson, 2019), or built environment designed for physical activity (Cefai, 2018; Chen et al., 2016; Goodman et al., 2019; Moroney \& Shilton, 2010). Community engagement in co-designing the built environment is a consistent and robust determinant of utilization. In a community where the locals were actively involved in the design and planning the types of preferred built environment, the utilization rate was higher than in a community where government neglected the views of the locals (Roberts et al., 2018). Community perception toward built environment features, such as availability, structured condition (function and aesthetics), closeness, connectivity to the surrounding environment, and safety also affect utilization (Handy et al., 2002; Heerman et al., 2016; Parra et al., 2010).

Apart from community participation, health equity is the core value of Healthy Cities (de Leeuw \& Green, 2017). Healthy space model (in the study) therefore, was defined as the provision of healthy spaces by redesigning or building the areas in the community by involving the locals in the planning and co-designing, with its ultimate goals being to bridge the inequalities in accessing physical activity 
amenities. The model selected several communities in four provinces (Bangkok, Phetchaburi, Nakhon Pathom and Nakon Sawan) with three foci: 1) Redesigning unused spaces and wasteland in the community (e.g. unused parks, under expressways, and along the beach or river) into sports complexes; 2) Designing creative city areas to improve walkability; 3) Providing space and activities for elderly-healthy community.

While sports complex and elderly-healthy community are common terms in urban or public health fields, the notion of creative city perhaps should be defined more clearly. Many creative city projects were designed based on each city's uniqueness, history, culture, strengths, weaknesses, and resources (Ashton et al., 1986). A creative city project also offers strategic paths for cities to develop more inclusive and sustainable economic growth patterns, such as IncrediBol in Bologna or Tapiskwan in Quebec which served the community not only as a strategic lever for economic attractiveness but also as a way to stimulate urban regeneration (UNESCO, 2019). Likewise, the creative city project under the healthy space model focused on redesigning the local market to improve its connectivity. Roads and walkways were rebuilt to attract more visitors and locals to walk along the market, while also encouraging physical activity. At the same time, it would stimulate the economic growth of the local community, which is beneficial in eliminating socioeconomic inequalities. The present study aims to assess the utilization of healthy spaces for PA as a measure of inequality in Thai communities. As the healthy space model involves the locals in co-designing and planning the built environment, we expected to see a high participation rate in all settings, and a higher PA level among the participating community members compared to non-participants.

\section{Methodology}

A cross-sectional, quantitative utilization survey was undertaken in March 2019 with a total of 2,046 community members, comprised of 1,523 residents who lived near a sports complex, 316 community members in the creative city model, and 207 members of elderly-healthy community. Face-to-face interviews were used to assess community usage of the built environment by asking whether respondents had ever visited a sports complex for PA, or whether they have participated in any activity related to the creative city or the elderly-healthy community. PA was retrospectively measured using GPAQ v2 by asking the respondents to assess their PA level, after which the healthy space model was established. T-test analysis was employed to compare the PA level of participating and non-participating community members in three types of the built environment under the healthy space model.

This study considered that barriers in community participation are partly caused by inequalities. Given that PA is differed by various biological and socioeconomic factors, we expect to see a different level of participation among the diverse communities. Thus, inequalities in PA are observed depending on 1) 
biological factor (age and sex), and 2) SES (income, education, occupation, and social support). As the Thai government planned to expand the healthy space model to a broader scale, the seven communities in four provinces were selected as pilot areas for model development and to represent an urban, suburban and rural population with different geography, SES and lifestyle. With three preconditions 1) strong community engagement, 2) commitment of the local government, and 3) the availability of spaces, those communities were considered ideal for representing the Thai population. It should be noted, however, that all the pilot projects had been in operation for about one to three years prior to the utilization survey.

Four sports complexes were observed: 1) Lankilaphat 1 and 2) Lankilaphat 2 (under the Urupong expressway) in Bangkok, 3) Baan Laem, and 4) Haad-ChaoSamran in Petchaburi Province. While Lankilaphat-1 and Lankilaphat-2 embodied an urban setting where the population is mostly working in the nonagricultural sector, Baan Laem and Haad-Chao-Samran in Phetchaburi exemplified a rural coastal area where agriculture (farming, fishery) was regarded as the main feature of living. The local community in the four settings were involved in the planning and co-designing of the sports complexes, with the financial support of Thai Health Promotion Foundation (Thai Health), Bangkok local government and the sub-district administrative organization of both areas.

The creative city near a local market in Muang District, Phetchaburi Province was observed. The creative city under the healthy space model adopted the example of UNESCO's creative cities (UNESCO, 2019) in redesigning the local market in Phetchaburi province to support an economically disadvantaged community with an improved built environment (roads, walkways) to attract locals and foreign tourists to visit the setting and accelerate economic growth and development of the locality.

Two elderly-healthy communities included: 1) Khao Thong in Nakhon Sawan Province, and 2) Baan Ua-Athon Phutthamonthon Sai 4 in Nakhon Pathom Province. While the rural Khao Tong was developed and funded by the community, the sub-urban Phutthamonthon Elderly Centre was funded by the Thai Health, community fundraising, and the sub-district administrative organization. The elderly healthy community program aimed to provide better living conditions for the seniors which focuses on three aspects: 1) Renovation of houses to become an elderly-friendly by building footpaths and handrails to enable safe movement; 2) PA; and 3) Long-term care, where health volunteers provide home visits and health check-ups on a regular basis.

\section{Results}

\section{Utilization of the built environment}

Overall, about a half $(48 \%)$ of the residents around sports complexes have used the facilities, while only $22 \%$ and $31 \%$ participated in the creative city and elderly- 
healthy community, respectively. Of the four sports complexes under observation, the built environment in Bangkok areas (Lankilaphat 1 and 2) was used more by the nearby residents $(63.8 \%$ and $47.9 \%$, respectively), compared to Baan Laem and Haad-Chao-Samran $(50.5 \%$ and $30.3 \%$, respectively) in Phetchaburi.

\section{Age and gender differences in built environment utilization}

The majority of sports complex users in all four settings were youth (Table 1), whereas adult and elderly were $74 \%$ and $79 \%$ less likely to use it (Table 2). Although the healthy space model was intended to equalize the opportunities of disadvantaged populations in accessing PA facilities, it is clear that several factors constrain the ability of community members to use the facilities. While it is expected that the built environment would facilitate access/utilization of community members of all ages, it seems that sports complexes are more favoured by the youth who have the freedom to visit and engage in PA. Creative city serves as an example of a non-age-specific intervention where all community members are expected to participate without any barrier. However, similar to sports complexes, adult and elderly were $80 \%$ and $88 \%$ less likely to participate in the creative city compared to youth (Table 2 ).

The effect of age on the utilization of built environment could also be seen in the elderly-healthy community (Table 1) where the proportions of the older-old (50-59) who participated in the activities (40\% in Khao-thong and $40.4 \%$ in Baan Ua-athon) were higher than the oldest-old $(60+)(27.9 \%$ and $20.5 \%$, respectively). Nevertheless, the multivariate analysis used found no significant effect of age on participation, which suggests that there was equal opportunity for all elderly to participate in healthy community activities (Table 2). While age differentiated the built environment users, there was no effect of gender and the presence of chronic disease on utilization (Table 2). In all healthy space models, the built environment provided equal opportunity for males and females to visit the sports complexes and to be involved in activities.

Table 1. Percentage of built environment users by gender and age group

\begin{tabular}{|c|c|c|c|c|c|c|c|}
\hline & \multicolumn{4}{|c|}{ Sports complexes } & \multirow[t]{2}{*}{$\begin{array}{c}\text { Creative } \\
\text { City }\end{array}$} & \multicolumn{2}{|c|}{$\begin{array}{c}\text { Elderly healthy } \\
\text { community }\end{array}$} \\
\hline & $\begin{array}{c}\text { Lankila- } \\
\text { phat-1 }\end{array}$ & $\begin{array}{l}\text { Lankila- } \\
\text { phat-2 }\end{array}$ & $\begin{array}{l}\text { Baan- } \\
\text { Laem }\end{array}$ & $\begin{array}{l}\text { Haad- } \\
\text { Chao- } \\
\text { Samran }\end{array}$ & & $\begin{array}{l}\text { Khao- } \\
\text { thong }\end{array}$ & $\begin{array}{c}\text { Baan- } \\
\text { Ua-athon }\end{array}$ \\
\hline & $(\mathrm{n}=381)$ & $(\mathrm{n}=380)$ & $(\mathrm{n}=382)$ & $(\mathrm{n}=380)$ & $(\mathrm{n}=316)$ & $(n=106)$ & $(\mathrm{n}=101)$ \\
\hline $\begin{array}{l}\text { Participation } \\
\text { rate }\end{array}$ & 63.8 & 47.9 & 50.5 & 30.3 & 21.5 & 30.2 & 31.7 \\
\hline Youth & 89.5 & 73.9 & 62.4 & 44.4 & 29.9 & 0.0 & 0.0 \\
\hline Adult & 55.8 & 44.2 & 50.0 & 30.3 & 20.1 & 40.0 & 40.4 \\
\hline Elderly & 58.1 & 24.6 & 36.1 & 11.5 & 17.5 & 27.9 & 20.5 \\
\hline Male & 66.8 & 48.6 & 49.2 & 26.5 & 22.0 & 22.2 & 33.3 \\
\hline Female & 60.9 & 47.2 & 51.8 & 33.8 & 21.1 & 32.9 & 30.4 \\
\hline
\end{tabular}


Table 2. Odds ratios of community utilization of the built environment in the health space model

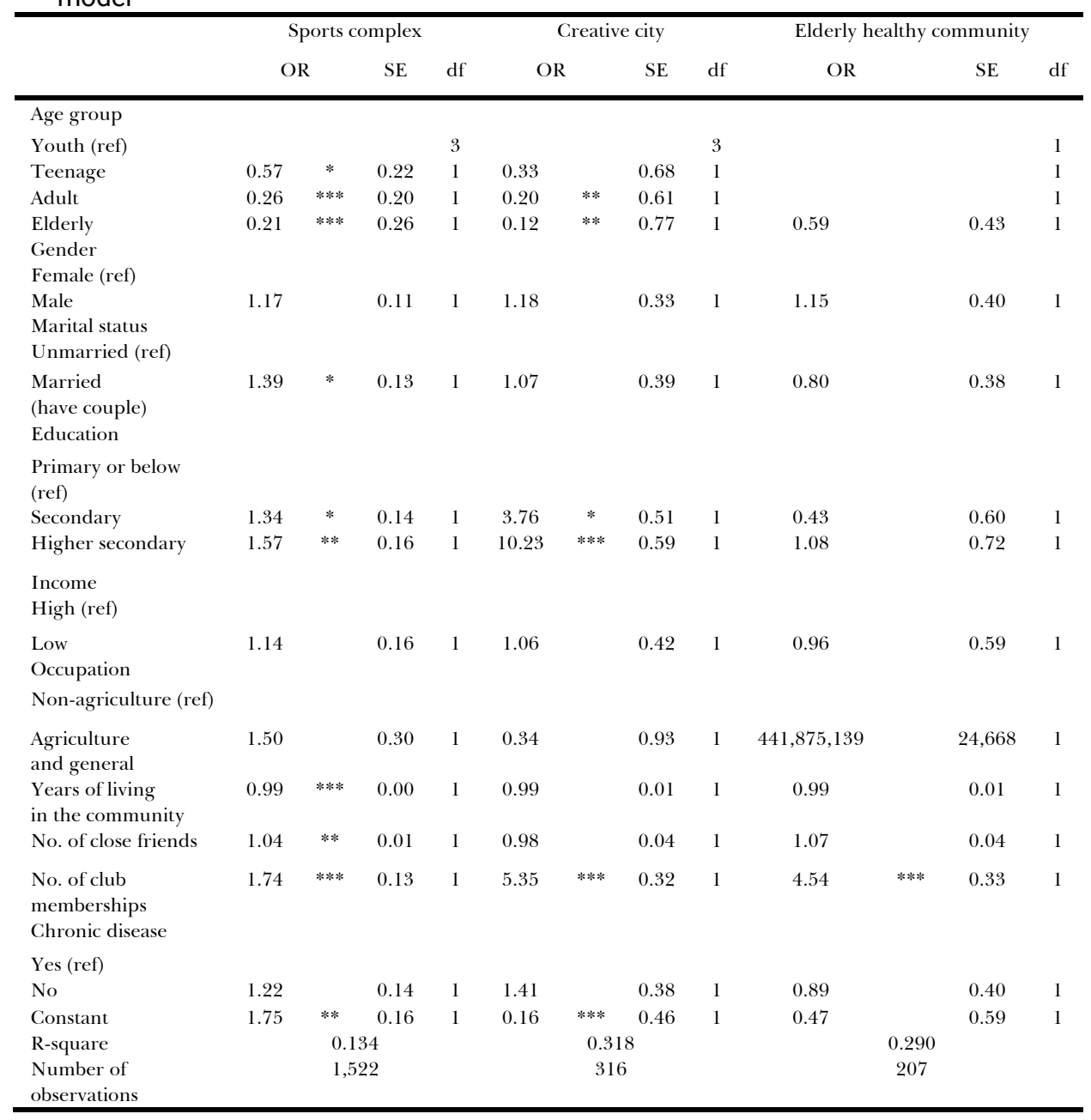

Likewise, the presence of chronic disease as an individual physical barrier appeared to have no significant influence on the utilization of the built environment since the sports complexes, creative city, and elderly community did not restrain members from using the facilities or participate in the activities (Table 2).

\section{Socioeconomic differences in built environment utilization}

Built environment was initially designed to provide community members with equal opportunity to access PA facilities. The participation rate of the community in the built environment under the healthy space model is clearly differed by educational attainment. While a considerable portion of sports complex users and creative city participants were youth (uncompleted primary) and adults with higher education (upper secondary), educational differences of the members in the elderly-healthy community are negligible (Table 3). 
Table 3. Percentage of built environment users by socioeconomic characteristics

\begin{tabular}{|c|c|c|c|c|c|c|c|}
\hline & \multicolumn{4}{|c|}{ Sports complexes } & \multirow{2}{*}{$\begin{array}{c}\text { Crea } \\
\text {-tive } \\
\text { city } \\
(\mathrm{n}=316) \\
\end{array}$} & \multicolumn{2}{|c|}{$\begin{array}{l}\text { Elderly healthy } \\
\text { community }\end{array}$} \\
\hline & $\begin{array}{c}\text { Lankila- } \\
\text { phat-1 } \\
(\mathrm{n}=381)\end{array}$ & $\begin{array}{c}\text { Lankila- } \\
\text { phat-2 } \\
(\mathrm{n}=380)\end{array}$ & $\begin{array}{l}\text { Baan- } \\
\text { Laem } \\
(\mathrm{n}=382)\end{array}$ & $\begin{array}{l}\text { Haad- } \\
\text { Chao- } \\
\text { Samran } \\
(\mathrm{n}=380)\end{array}$ & & $\begin{array}{l}\text { Khao- } \\
\text { thong } \\
(\mathrm{n}=106)\end{array}$ & $\begin{array}{l}\text { Baan- } \\
\text { Ua- } \\
\text { athon } \\
(\mathrm{n}=101)\end{array}$ \\
\hline $\begin{array}{l}\text { Participation rate } \\
\text { Education }\end{array}$ & 63.8 & 47.9 & 50.5 & 30.3 & 21.5 & 30.2 & 31.7 \\
\hline Without primary & 100.0 & 25.0 & 33.3 & 33.3 & 33.3 & 29.4 & 0.0 \\
\hline Primary school & 60.9 & 46.1 & 45.1 & 27.5 & 9.2 & 27.3 & 36.8 \\
\hline Secondary school & 72.9 & 49.2 & 55.9 & 34.8 & 20.6 & 55.6 & 12.5 \\
\hline Vocational & 57.5 & 52.8 & 70.8 & 15.4 & 25.0 & 100.0 & 40.0 \\
\hline Bachelor's degree & 55.1 & 46.2 & 71.4 & 28.6 & 34.2 & 0.0 & 50.0 \\
\hline Postgraduate & 76.9 & 0.0 & 50.0 & 0.0 & 28.6 & 0.0 & 0.0 \\
\hline Other & 0.0 & 100.0 & 0.0 & 75.0 & 0.0 & 0.0 & 0.0 \\
\hline Income (bahts) & & & & & & & \\
\hline Below 3,501 & 78.6 & 57.4 & 51.6 & 33.1 & 26.3 & 27.1 & 29.4 \\
\hline $3,501-10,000$ & 57.1 & 41.6 & 42.4 & 29.1 & 5.8 & 38.7 & 25.0 \\
\hline $10,001-15,000$ & 55.4 & 42.7 & 51.6 & 24.4 & 26.5 & 18.2 & 38.5 \\
\hline $15,001-30,000$ & 58.3 & 40.4 & 75.0 & 37.0 & 26.0 & 0.0 & 33.3 \\
\hline $30,001-50,000$ & 57.7 & 50.0 & 80.0 & 27.3 & 21.9 & 0.0 & 60.0 \\
\hline $50,001-100,000$ & 71.4 & 50.0 & 50.0 & 33.3 & 30.0 & 0.0 & 0.0 \\
\hline $100,001-300,000$ & 0.0 & 60.0 & 0.0 & 0.0 & 60.0 & 0.0 & 0.0 \\
\hline Over 300,000 & 0.0 & 0.0 & 0.0 & 0.0 & 0.0 & 0.0 & 0.0 \\
\hline No answer & 56.5 & 0.0 & 59.1 & 25.0 & 0.0 & 100.0 & 0.0 \\
\hline Occupation & & & & & & & \\
\hline $\begin{array}{l}\text { Health-related } \\
\text { unemployed }\end{array}$ & 42.9 & 33.3 & 8.3 & 10.0 & 0.0 & 36.4 & 38.5 \\
\hline Unemployed & 33.3 & 66.7 & 62.5 & 0.0 & 0.0 & 0.0 & 0.0 \\
\hline Student & 85.7 & 75.6 & 66.3 & 44.3 & 30.4 & 0.0 & 0.0 \\
\hline Government official & 45.0 & 50.0 & 87.5 & 43.8 & 30.0 & 0.0 & 57.1 \\
\hline Company employee & 59.2 & 37.5 & 54.5 & 33.3 & 36.4 & 0.0 & 16.7 \\
\hline Own business/trade & 55.4 & 39.5 & 53.7 & 30.6 & 19.7 & 33.3 & 21.1 \\
\hline Agriculture & 0.0 & 66.7 & 46.8 & 26.5 & 0.0 & 31.8 & 0.0 \\
\hline Retired & 75.0 & 25.0 & 0.0 & 0.0 & 6.3 & 0.0 & 33.3 \\
\hline Housewife/domestic & 53.7 & 38.1 & 52.5 & 18.5 & 29.4 & 16.0 & 23.1 \\
\hline General contractor & 59.5 & 37.5 & 38.2 & 24.1 & 17.8 & 50.0 & 40.7 \\
\hline
\end{tabular}

Logistic regression analysis found that for individuals who resided near a sports complex, being a secondary school graduate was associated with more opportunity (1.34 times) for the use the sports complex for PA compared to those with primary education or below. Furthermore, upper secondary graduates were 1.57 times more likely to use the facilities. Residents of the creative city who attained secondary school education were 3.76 times more likely to participate, whereas those who completed upper secondary school had 10.23 times the odds of being involved in the activities (Table 2). 
Income was not a significant predictor of utilization of all types of the built environment, which means all community members - regardless of income level had an equal chance to use the facilities or participate in the available amenities. It should be noted, however, that the built environments were designed at the community level with the primary purpose to serve the local community residing nearby, which usually was comprised of a homogenous group. Therefore, although community usage of the built environment was almost equally distributed across all income levels within the same group of the population, a considerable proportion of higher-income participants (above 30,000 baht per month) was found in urban settings such as Lankilaphat-1, Lankilaphat-2 and Baan Laem (71.4\%, 60\%, and 80\%, respectively) (Table 3).

Logistic regression analysis found that occupation was also insignificant in predicting utilization in all settings (Table 2). Whatever their occupation, the locals enjoyed equal access to the sports facility or participate in the activities, although initially, it was expected that working hours would affect the level of utilization. With a higher participation rate among students and retirees in Lankilaphat- 1 ( $85.7 \%$ and $75 \%$, respectively), we assumed that working-age adults had less opportunity to use the sports complex, compared to students and retirees - who may have more flexibility in managing their leisure activities.

Likewise, those in agricultural occupations (such as farmer or fisherman) who have unpredictable working hours, were expected to have less chance to visit the sports complex or participate in any activity compared to office workers with stable working hours. However, further analysis of the occupation based on the stability of work hours and duration of work, showed there was no difference in built environment utilization between those who had stable working hours (office workers) versus those with unstable hours (agriculture and temporary contract workers) because the facilities could be accessed at any time of day or night at their convenience. Marital status only affected sports complex utilization. Compared to a single person, a married person was 1.39 times more likely to visit a sports complex for PA. Apart from the spouse, individuals who had an extensive number of close friends were 1.04 times more likely to visit a sports complex for PA compared to those who had only a few close friends (Table 2). With similar reasons as a spouse, the presence of close friends implying the number of supports that individuals might obtain from their networks to use the sports complex and engage in collective physical activity.

One or more club memberships implies more support an individual might gain, both in terms of facilities or group support for collective PA. In all three built environment settings, the number of club memberships significantly predicted built environment utilization. In other words, the more clubs someone registered with, the higher their likelihood to use a sports complex (odds ratio $=1.74$ ) or participate in creative city activities (odds ratio $=5.35$ ), and elderly -healthy community (odds ratio=4.54). Years of living in the community, on the contrary, was inversely associated with sports complex utilization. The longer an individual resided in the community, the less $\mathrm{s} / \mathrm{he}$ was likely to visit a sports complex. There was no significant evidence of the effect of living duration on participation in the creative city or elderly community. 


\section{Sufficient $P A$}

Sufficient PA was defined based on the WHO recommendation of 60-minutes daily for children and youth, and an accumulation of 150-minutes of MVPA, or 75-minutes of vigorous PA, per week for adults. T-test results indicate that sufficient MVPA was more prevalent among those who participated in the program, i.e. $81.3 \%$ versus $67.2 \%$ among the residents who lived near a sports complex $(\mathrm{t}=6.387 * * *), 86.8 \%$ versus $79 \%(\mathrm{t}=1.583)$ of the creative city; and $84.4 \%$ versus $72.7 \%(\mathrm{t}=1.972 *)$ among the members of the elderly-healthy community (Table 4). Reported PA of non-participating residents in the healthy space model was also higher compared to those who lived in an area with no healthy space program available.

\section{Discussion}

There is a bulk of evidence that environment is a consistent predictor of PA (Kenyon, 2018; Liangruenrom et al., 2019; Loh et al., 2019; Sallis et al., 2015; Watson, 2019). Individuals who reside in a supportive environment for PA are more likely to have better health practices than those who live in a community with a lack of environmental support (Sallis et al., 2012; 2015). Built environments, therefore, are designed to bridge the socioeconomic barriers to PA, particularly for disadvantaged populations with limited access to PA facilities such as a gym, fitness centre, or park. Nevertheless, amid the massive healthy lifestyle campaigns and various health promotion interventions, including built environment for PA, this study found that some facilities were not optimally utilized, as shown by $48 \%$ utilization of the local sports complex. A community's low engagement is also indicated by the relatively low participation in the creative city and the elderly-healthy communities (22\% and $31 \%$, respectively).

Although sufficient PA was found to be higher among community members who participated in the healthy space model (compared to non-participants), there is room for improvement by understanding which group of the population utilizes these amenities and which do not, and why. As built environment aimed to overcome socioeconomic barriers, low participation may be interpreted as a persistent obstacle for the disadvantaged in society. Given the significant odds ratio in the logistic regression (representing inequality in accessing built environment) and insignificant results (considered as equality), this study found that not all built environment types could eliminate inequalities due to demographic factors such as age.

Table 4. Comparison of communities with sufficient MVPA in the healthy space model

\begin{tabular}{lccc}
\hline & Participant & Non-participant & T-test \\
\hline Sports complex $(\mathrm{n}=1,523)$ & 81.3 & 67.2 & $6.387^{* * *}$ \\
Creative City $(\mathrm{n}=316)$ & 86.8 & 79.0 & 1.583 \\
Elderly Healthy Community $(\mathrm{n}=207)$ & 84.4 & 72.7 & $1.972^{*}$ \\
\hline
\end{tabular}


Although they are intended for use by all population groups, the sports complex and creative city did not attract working-age adults who may be preoccupied with their daily tasks, or the elderly with limited physical ability.

It should be noted, however, that while youth and retirees might have limited options for engaging in PA (except for the sports complex near home), workingage adults engaged in PA elsewhere. The findings from this research suggest that adults had a preference for open space near parks or workplace facilities to engage in PA, perhaps out of the need to be socially engaged with their colleagues (Iwasaki et al., 2017; Levy-Storms et al., 2018; Xiao et al., 2019).

The healthy space model has shown its capacity for removing gender-based inequalities by providing an equal chance for males and females to visit the sports complex and be involved in the availaible activities. As women's empowerment has become a more popular trend in contemporary Thailand, gender equality norms have granted many Thai women more freedom of movement, including pursuing higher education, having independent employment/income, and sharing an equal distribution of housework with their male partner (Akter et al., 2017; Najafizadeh \& Lindsey, 2018; Pimpa et al., 2017). With equal decisionmaking power in the household, Thai women now enjoy more freedom in allocating personal time for their family and themselves, including planning their PA. Unfortunately, the healthy space model could only partially remove social inequality driven by educational attainment. The insignificant effect of education on the participation of elderly-healthy community members implies that, in the homogenous elderly population, every member had an equal chance to participate in activities regardless of their educational attainment. Sports complex and creative city, however, could not eliminate educational-related inequalities since individuals with higher educational attainment were more likely to have a better awareness of PA and, therefore, increased probability of using the facilities (Waters \& Hawkins, 2018; Williamson, 2016).

While the effect education has is most likely also correlated with a person's occupation, our analysis did not find any occupation as significance in the utilization of the built environment, which means it was able to remove occupation-related inequalities. Since the built environment was designed to provide equal access, community members, regardless of their occupation, could access the sports complex and participate in the associated activities at their convenience. The healthy space model (sports complex, creative city, and elderlyhealthy community) have succeeded in eliminating the income-driven inequalities, as shown by the insignificant effect of income on the utilization of the built environment. All community members residing near the facilities had equal opportunity to be involved. Although the research found that a higher proportion of high earners participated in the amenities in urban settings (Lankilaphat-1, Lankilaphat-2), a community's characteristics, instead of individual barriers, seemed to be the more plausible explanation for built environment utilization.

It is true that higher SES creates more opportunities for better-off members of the community. The combination of education, income, and occupation that define SES has been found to be a strong and consistent predictor of inequities in 
PA worldwide (Beenackers et al., 2012; Hanibuchi, Nakaya, \& Honjo, 2016; Kamphuis \& van Lenthe, 2013; Loh, Rachele, et al., 2019). However, as expected, this study found that the built environment bridged the socioeconomic inequalities in the community by providing equal access for all community members.

Although built environment could eliminate most socioeconomic inequalities, it was not able to completely remove the social support disparities such as those associated with marital status, number of close friends, and number of club memberships. As marital status implies support, married individuals received adequate support from their spouse and had a steady partner with whom to engage in regular PA. While marital status was associated with inequality in sports complex utilization, the logistic regression analysis showed that it did not predict participation in the creative city and elderly-healthy community. These results imply that various activities in the creative city and elderly-healthy community provided equal opportunity for either married or unmarried individuals to be actively involved. Being a couple in these communities could be interpreted as having an additional support mechanism, apart from the existing motivation from community members who joined the club(s).

The number of close friends only had an effect on sports complex utilization, whereas the number of club memberships determined community participation in all settings. Individuals who had more friends were more likely to use the sports complex, whereas those who registered in various clubs had more opportunity to use all types of the built environment and activities (sports complex, creative city and elderly-healthy community). Although the significance of close friends and club membership on the utilization of built environment implies inequality, both factors influence PA and should not be eliminated. Social support from various sources such as family, friends/peers, and significant others have been identified as reinforcing factors of PA, particularly for individuals with lower self-efficacy (Hohepa et al., 2007; Laird et al., 2016; Sarkar et al., 2016; Scarapicchia et al., 2017). While children relied on their family, adolescents are more likely to seek support from their friends/peers to engage in regular PA (Hohepa et al., 2007). Social support from their co-workers is also an important correlating factor of PA for adults (Scarapicchia et al., 2017).

It is interesting to observe the effect of the healthy space model in differing levels of PA for the community members. While T-test statistical analysis found a significant difference in the proportion of the community with sufficient MVPA between users and non-users of the sports complex and elderly-healthy community, there was no significant difference in the MVPA of the members of the creative city. Limitation in the participation measurement could be one of the explanations for this finding; i.e. creative city mainly aims to improve the socioeconomic livelihood of the community by redesigning roads and walkways around the market. Unlike sports complex and elderly-healthy community, which specify PA as one of the indicators of participation, creative city participation was measured by indicators of involvement in the neighbourhood. 
The nature of the cross-sectional survey in measuring PA in relation to builtenvironment utilization is perhaps a limitation of the study. The survey could not capture whether the PA level was the actual result of utilizing the built environment or derived from other health promotion programs and campaigns. A post-test only design was employed because the built environments under the healthy space model had been established in the community for several years and, thus, there was no baseline for comparison. Secondly, while the utilization survey focused on community usage of the built environment and PA, it failed to capture the PA of individuals outside the study setting. The low utilization of the sports may complex among the working-age group could be explained by their visiting facilities outside the study area, such as fitness centres or parks near their workplace. Despite its limitations, the present study adds several insights to the PA body of knowledge. By using the limited data available, the study assessed the effect of the built environment to a community's healthy behaviour by comparing the PA of participants and non-participants. In addition, the study identified socioeconomic inequalities as one of the factors behind low participation. The results of the study should be useful as evidence for policymakers in designing a better built environment which produces higher community engagement.

\section{Conclusions}

Built environment under the healthy space model could eliminate most socioeconomic inequalities but could not remove physical-ability and social support inequalities. Although the low level of participation is undeniable, the provision of a sports complex, creative city, and elderly-healthy community have encouraged community members who live in the study area to be more active. As it is challenging to erase physical-ability inequalities, improvement in social support could be important in encouraging community members to register with any club of their interest to increase their engagement in collective activities, particularly in using the built environment.

The healthy space model could be applied in various settings with similar characteristics but require these preconditions: community engagement, government support and the availability of areas to be rebuilt or redesigned. The model could also be employed in diverse communities since it targeted both specific group of population (elderly-healthy community) and the general population (sport complex and creative city) to ensure equal access to PA facilities in the neighbourhood. The Thailand model also serves as an example for lowmiddle income countries where socioeconomic inequalities could not be neglected, whereas PA facilities should be made available and accessible for its population to improve their living standard. The community engagement as the key of the model therefore is crucial, not only to make sure high participation but also in maintaining the built environment for physical activity. 


\section{Acknowledgments}

The authors thank Arsom Silp Institute of Art for their contribution to the project.

\section{References}

Akter, S., Rutsaert, P., Luis, J., Htwe, N. M., San, S. S., Raharjo, B. and Pustika, A. (2017), "Women's empowerment and gender equity in agriculture: A different perspective from Southeast Asia", Food Policy, vol. 69, p. 270-279.

Ashton, J., Grey, P. and Barnard, K. (1986), "Healthy cities-WHO's new public health initiative", Health promotion international, vol. 1, no. 3, p. 319-324.

Beenackers, M.A., Kamphuis, C.B., Giskes, K., Brug, J., Kunst, A.E., Burdorf, A. and Van Lenthe, F.J. (2012), "Socioeconomic inequalities in occupational, leisure-time, and transport related physical activity among European adults: a systematic review", International journal of behavioral nutrition and physical activity, vol. 9, no. 1, p. 1-23.

Cefai, C. (2018), "Healthy Habits and Healthy Spaces: Children's Views on Their Use of Time and Space' in L.R. de la Vega and W..N Toscano (eds.) Handbook of Leisure, Physical Activity, Sports, Recreation and Quality of Life, p. 97-105, Springer.

Chandrasiri, O. and Arifwidodo, S. (2017), "Inequality in active public park: a case study of Benjakitti Park in Bangkok, Thailand", Procedia engineering, vol. 198, p. 193-199.

Chase, E. (2018), "Sports and Recreation: Inequalities for Young Children with Regards to Sports and Physical Activity", in B. Johnson and Y. Pratt-Johnson (eds.) Inequalities in the Early Years, p. 127-136, Routledge.

Chen, T., Hui, E. C.-M., Lang, W. and Tao, L. (2016), "People, recreational facility and physical activity: New-type urbanization planning for the healthy communities in China", Habitat International, vol. 58, p. 12-22.

de Leeuw, E. and Green, G. (2017), The logic of method for evaluating healthy cities", in E. de Leeuw and J. Simos (eds.) Healthy Cities, p. 463-487, Springer, New York.

Demarest, S., Van Oyen, H., Roskam, A.-J., Cox, B., Regidor, E., Mackenbach, J. P. and Kunst, A.E. (2014), "Educational inequalities in leisure-time physical activity in 15 European countries", The European Journal of Public Health, vol. 24, no. 2, p. 199-204.

Giles-Corti, B. (2016), "Could public policies reduce inequalities in physical activity and health?", Revista Brasileira de Atividade Física E Saúde, vol. 21, no. 1, p. $1-4$.

Goodman, A., Snyder, M., Wilson, K. and Whitford, J. (2019), "Healthy spaces: Exploring urban Indigenous youth perspectives of social support and health using photovoice", Health छ place, vol. 56, p. 34-42.

Gordon-Larsen, P., Nelson, M. C., Page, P. and Popkin, B.M. (2006), "Inequality in the built environment underlies key health disparities in physical activity and obesity", Pediatrics, vol. 117, no. 2, p. 417-424. 
Handy, S.L., Boarnet, M.G., Ewing, R. and Killingsworth, R.E. (2002), "How the built environment affects physical activity: views from urban planning", American journal of preventive medicine, vol. 23, no. 2, p. 64-73.

Hanibuchi, T., Nakaya, T. and Honjo, K. (2016), "Trends in socioeconomic inequalities in self-rated health, smoking, and physical activity of Japanese adults from 2000 to 2010", SSM-population health, vol. 2, p. 662-673.

Heerman, W.J., Mitchell, S.J., Thompson, J., Martin, N.C., Sommer, E.C., van Bakergem, M., Taylor, J.L., Buchowski, M.S and Barkin, S.L. (2016), "Parental perception of built environment characteristics and built environment use among Latino families: a cross-sectional study", BMC public health, vol. 16, no. 1, pp. 1180.

Hohepa, M., Scragg, R., Schofield, G., Kolt, G.S. and Schaaf, D. (2007), "Social support for youth physical activity: Importance of siblings, parents, friends and school support across a segmented school day", International journal of behavioral nutrition and physical activity, vol. 4, no. 1, p. 4-54.

IPSR (2016), Thailand Physical Activity Surveillance 2016 Dataset, Bangkok, Thailand: Institute for Population and Social Research, Mahidol University.

IPSR (2017), Thailand Physical Activity Surveillance 2017 Dataset, Bangkok, Thailand: Institute for Population and Social Research, Mahidol University.

International Society for Physical Activity and Health (2017), "The Bangkok Declaration on Physical Activity for Global Health and Sustainable Development", British Journal of Sports Medicine, vol. 51, no. 19, 1389.

Iwasaki, Y., Honda, S., Kaneko, S., Kurishima, K., Honda, A., Kakinuma, A. and Jahng, D. (2017), "Exercise self-efficacy as a mediator between goal-setting and physical activity: developing the workplace as a setting for promoting physical activity", Safety and health at work, vol. 8, no. 1, p. 94-98.

Jitsuchon, S. (2020), Thai inequality: What we should know, Bangkok Post.

Kamphuis, C. and van Lenthe, F. (2013), "Socioeconomic differences in physical activity: the role of neighbourhood factors" in C. Stock and A. Ellaway Neighbourhood Structure and Health Promotion, p. 223-248, Springer.

Kärmeniemi, M., Lankila, T., Ikäheimo, T., Koivumaa-Honkanen, H. and Korpelainen, R. (2018), "The built environment as a determinant of physical activity: a systematic review of longitudinal studies and natural experiments", Annals of Behavioral Medicine, vol. 52, no. 3, p. 239-251.

Kenyon, A. (2018), "Built environment, walking and health inequalities in urban Scotland", PhD Thesis, School of Geosciences, University of Edinburg, Scotland. Laird, Y., Fawkner, S., Kelly, P., McNamee, L., and Niven, A. (2016), "The role of social support on physical activity behaviour in adolescent girls: a systematic review and meta-analysis", International journal of behavioral nutrition and physical activity, vol. 13, no. 1, p. 13-79.

Levy-Storms, L., Chen, L. and Loukaitou-Sideris, A. (2018), "Older adults' needs and preferences for open space and physical activity in and near parks: A systematic review", Journal of aging and physical activity, vol. 26, no. 4, p. 682-696. 
Liangruenrom, N., Craike, M., Biddle, S.J., Suttikasem, K. and Pedisic, Z. (2019), "Correlates of physical activity and sedentary behaviour in the Thai population: a systematic review", BMC public health, vol. 19, no. 1, p. 1-26.

Loh, V.H., Rachele, J.N., Brown, W.J., Ghani, F., Washington, S. and Turrell, G. (2019), "The potential for walkability to narrow neighbourhood socioeconomic inequalities in physical function: A case study of middle-aged to older adults in Brisbane, Australia", Health E place, vol. 56, p. 99-105.

Loh, V. H., Veitch, J., Salmon, J., Cerin, E., Thornton, L., Mavoa, S., Villanueva, K. and Timperio, A. (2019), "Built environment and physical activity among adolescents: the moderating effects of neighborhood safety and social support", International journal of behavioral nutrition and physical activity, vol. 16, no. 1.

MoPH (2017), 5-Year National NCDs Prevention and Control Strategic and Action Plan (2017-2021), Ministry of Public Health.

Moroney, A. and Shilton, T. (2010), "Healthy spaces and places", Journal of Science and Medicine in Sport, vol. 12, p. e56-e57.

Najafizadeh, M. and Lindsey, L. (2018), Women of Asia: Globalization, Development, and Gender Equity, Routledge.

Parra, D.C., Gomez, L.F., Fleischer, N.L. and Pinzon, J.D. (2010), "Built environment characteristics and perceived active park use among older adults: Results from a multilevel study in Bogota", Health $\xi$ place, vol. 16, no. 6, p. 11741181.

Petersen, A. (1996), "The 'healthy' city, expertise, and the regulation of space", Health E place, vol. 2, no. 3, p. 157-165.

Picavet, H.S.J., Milder, I., Kruize, H., de Vries, S., Hermans, T. and Wendel-Vos, W. (2016), "Greener living environment healthier people?: Exploring green space, physical activity and health in the Doetinchem Cohort Study", Preventive medicine, vol. 89, p. 7-14.

Pimpa, N., Moore, T. and Phouxay, K. (2017), Unlocking Gender Potential. A Comparative Study of Women in the Mining Community in Thailand and Lao PDR, GRIN Publishing.

Roberts, H., McEachan, R., Margary, T., Conner, M. and Kellar, I. (2018), "Identifying effective behavior change techniques in built environment interventions to increase use of green space: a systematic review", Environment and Behavior, vol. 50, no. 1, p. 28-55.

Sallis, J.F., Floyd, M.F., Rodríguez, D.A. and Saelens, B.E. (2012), Role of built environments in physical activity, obesity, and cardiovascular disease, Circulation, vol. 125, no. 5, p. 729-737.

Sallis, J.F., Owen, N. and Fisher, E. (2015), "Ecological models of health behavior", Health behavior: Theory, research, and practice, vol. 5, p. 43-64.

Saonuam, P., Rasri, N., Pongpradit, K., Widyastari, D.A. and Katewongsa, P. (2018), "Results from Thailand's 2018 report card on physical activity for children and youth", Journal of Physical Activity and Health, vol. 15( 2), p. 417-418.

Sarkar, S., Taylor, W.C., Lai, D., Shegog, R. and Paxton, R.J. (2016), "Social support for physical activity: Comparison of family, friends, and co-workers", Work, vol. 55, no. 4, p. 893-899. 
Scarapicchia, T.M.F., Amireault, S., Faulkner, G. and Sabiston, C.M. (2017), "Social support and physical activity participation among healthy adults: a systematic review of prospective studies", International Review of Sport and Exercise Psychology, vol. 10, no. 1, p. 50-83.

Slater, S., Pugach, O., Lin, W. and Bontu, A. (2016), "If you build it will they come? Does involving community groups in playground renovations affect park utilization and physical activity?", Environment and Behavior, vol. 48, no. 1, p. 246265.

Sones, M., Fuller, D., Kestens, Y. and Winters, M. (2019), "If we build it, who will come? The case for attention to equity in healthy community design", British Journal of Sports Medicine, Publishing Group Ltd and British Association of Sport and Exercise Medicine.

UNESCO (2019), UNESCO Creative cities moving towards the 2030 agenda for sustainable development, France.

Waters, E.A. and Hawkins, E. (2018), "Awareness of Health Outcomes Associated with Insufficient Physical Activity and Associations with Physical Activity Intentions and Behavior", Journal of health communication, vol. 23, no. 7, p. 634642.

Watson, M. (2019), Exploring the role of greenspace and neighbourhood level inequalities in determining physical activity, health and wellbeing outcomes in young people in Aberdeen City, University of Aberdeen.

WHO (2013), Global action plan for the prevention and control of non-communicable diseases 2013-2020, World Health Organization.

Williamson, J. (2016), "Awareness of physical activity health benefits can influence participation and dose", Sports Medicine and Rehabilitation Journal, vol. 1, no. 1.

Xiao, Y., Wang, H., Zhang, T. and Ren, X. (2019), "Psychosocial predictors of physical activity and health-related quality of life among Shanghai working adults", Health and quality of life outcomes, vol. 17, no. 1.

Zhang, R., Duan, Y., Brehm, W. and Wagner, P. (2019), "Socioecological correlates of park-based physical activity in older adults: a comparison of Hong Kong and Leipzig parks", International journal of environmental research and public health, vol. 16, no. 17, pp. 3048 . 